IZA DP No. 9816

Business Cycle Asymmetries and the Labor Market

Britta Kohlbrecher

Christian Merkl

March 2016

Forschungsinstitut

zur Zukunft der Arbeit

Institute for the Study

of Labor 


\title{
Business Cycle Asymmetries and the Labor Market
}

\author{
Britta Kohlbrecher \\ Friedrich-Alexander-University Erlangen-Nuremberg \\ Christian Merkl \\ Friedrich-Alexander-University Erlangen-Nuremberg \\ and IZA
}
Discussion Paper No. 9816
March 2016

\author{
IZA \\ P.O. Box 7240 \\ 53072 Bonn \\ Germany \\ Phone: +49-228-3894-0 \\ Fax: +49-228-3894-180 \\ E-mail: iza@iza.org
}

\begin{abstract}
Any opinions expressed here are those of the author(s) and not those of IZA. Research published in this series may include views on policy, but the institute itself takes no institutional policy positions. The IZA research network is committed to the IZA Guiding Principles of Research Integrity.

The Institute for the Study of Labor (IZA) in Bonn is a local and virtual international research center and a place of communication between science, politics and business. IZA is an independent nonprofit organization supported by Deutsche Post Foundation. The center is associated with the University of Bonn and offers a stimulating research environment through its international network, workshops and conferences, data service, project support, research visits and doctoral program. IZA engages in (i) original and internationally competitive research in all fields of labor economics, (ii) development of policy concepts, and (iii) dissemination of research results and concepts to the interested public.
\end{abstract}

IZA Discussion Papers often represent preliminary work and are circulated to encourage discussion. Citation of such a paper should account for its provisional character. A revised version may be available directly from the author. 
IZA Discussion Paper No. 9816

March 2016

\section{ABSTRACT}

\section{Business Cycle Asymmetries and the Labor Market ${ }^{*}$}

This paper shows that the matching function and the Beveridge curve in the United States exhibit strong nonlinearities over the business cycle. These patterns can be replicated by enhancing a search and matching model with idiosyncratic productivity shocks for new contacts. Large negative aggregate shocks move the hiring cutoff point into a part of the idiosyncratic density function with higher density and thereby generate large, asymmetric jobfinding rate and unemployment reactions. Our proposed mechanism is of high relevance as it leads to time varying effects of certain policy interventions.

JEL Classification: E24, E32, J63, J64

Keywords: business cycle asymmetries, matching function, Beverdige curve, job-finding rate, unemployment, effectiveness of policy

Corresponding author:

Christian Merkl

Friedrich-Alexander-Universität Erlangen-Nürnberg

Chair of Macroeconomics

Lange Gasse 20

90403 Nürnberg

Germany

E-mail: christian.merkl@fau.de

\footnotetext{
* We thank Kilian Ruppert for excellent research assistance. In addition, the authors would like to thank Sanjay Chugh, Britta Gehrke, Brigitte Hochmuth, Ricardo Reis, Ayşegül Şahin, Peter Sedlácek, Fabio Schiantarelli, Robert Shimer, Gianluca Violante, Franceso Zanetti, Roland Winkler, Randy Wright and participants at seminars at Boston College, the EU Commission, Humboldt University, IZA, ILO, IAB and the CREI-EES workshop for very valuable feedback.
} 


\section{Introduction}

The labor market in the United States shows strong nonlinear patterns over the business cycle. It is well known that unemployment moves more in recessions than in booms (Abbritti and Fahr, 2013; McKay and Reis, 2008). In addition, in recessions the Beveridge curve shifts outwards (Diamond and Şahin, 2014) and the matching efficiency seems to fall (Barnichon and Figura, 2015). We argue that all these facts are related and can be explained theoretically by taking into account that the idiosyncratic quality of matches changes over the business cycle.

The shift of the Beveridge curve in the Great Recession has received a lot of interest recently (see e.g. Gavazza et al., 2015; Lubik, 2013). Diamond and Şahin (2014) show that this outward shift of the Beveridge curve is not unique to the recent crisis but can be observed in eight out of nine post war recessions. Interestingly, we find that the Beveridge curve does not systematically shift inwards in booms. The dynamic adjustment path of the search and matching model can at least partly explain why the Beveridge curve shifts outwards in recessions (Christiano et al., 2015). However, it does not provide a rationale for why the movement of the Beveridge curve is different in booms and recessions. The asymmetric behavior of the Beveridge curve can also be observed when looking at longer time series of the annual growth rates of vacancies and unemployment. ${ }^{1}$ The curvature of the Beveridge curve changes very much for large positive unemployment deviations. These observations, in turn, are related to the asymmetric movement of the job-finding rate and unemployment over the business cycle. The job-finding rate falls a lot more in recessions than it increases in booms and unemployment rises a lot more in recessions than it declines in booms (see also Abbritti and Fahr, 2013; Ferraro, 2016; McKay and Reis, 2008). By contrast, market tightness and vacancies move symmetrically over the business cycle. The asymmetric movements of the job-finding rate and the symmetric movement of market tightness explain why the matching function also exhibits strong nonlinearities. In deep recessions, it appears as if the job-finding rate is too low compared to market tightness and hence matching efficiency seems to fall (see e.g. Gavazza et al., 2015; Barnichon and Figura, 2015). This fact is difficult to reconcile with a standard search and matching model. ${ }^{2}$

This paper shows that all these stylized facts can be explained by enhancing a search and matching model with a labor selection mechanism. Under labor selection, after a contact is established between workers and firms, a match-specific idiosyncratic productivity shock is drawn. Some contacts are more productive than others and not every contact results in a hire. ${ }^{3}$ Em-

\footnotetext{
${ }^{1}$ Annual growth rates are the common filtering technique in the business cycle asymmetries literature (Abbritti and Fahr, 2013; McKay and Reis, 2008).

${ }^{2}$ By standard search and matching model, we refer to Pissarides (2000, chapter 1).

${ }^{3}$ For pure labor selection models and their implications, see Brown et al. (2015), Chugh
} 
ployers choose an optimal cutoff point of idiosyncratic productivity up to which they are willing to hire because applicants are sufficiently productive to generate an expected profit. The cutoff point and thereby the selection rate vary over the business cycle. ${ }^{4}$ During a recession, the marginal and average hired workers have larger idiosyncratic productivity than during a boom. The labor selection mechanism is able to generate asymmetric reactions of the job-finding rate and symmetric reactions of vacancies and market tightness in response to symmetric aggregate shocks.

What is the underlying intuition? In a recession, only workers with large idiosyncratic productivity are selected. If the cutoff point is located at an upward sloping part of the density function, a negative productivity shock will move the cutoff point of idiosyncratic productivity to a part of the distribution with higher density. Thus, for a given change in the present value, the selection rate and thereby the job-finding rate moves by more in a recession than in a boom. This generates the asymmetries of the job-finding rate that can be observed in the data. In addition, when firms post vacancies, they anticipate that they will hire workers with higher idiosyncratic productivity in a recession. This causes a composition effect that mutes the response of vacancies. By looking at the resulting behavior of the job-finding rate and market tightness through the lens of a standard matching function, it appears as if the job-finding rate has dropped too much relative to the market tightness. As a consequence, the measured matching efficiency, defined as the ratio between the actual job-finding rate and its prediction from a standard, time invariant matching function, would fall in a recession. When we solve for the fully nonlinear dynamic path of our model, the measured matching efficiency drops by around one quarter in the largest labor market downswing. This shows that our mechanism is quantitatively meaningful and contributes to the debate on potential reasons for a drop of the matching efficiency in severe recessions (see Gavazza et al., 2015; Barnichon and Figura, 2015).

The described theoretical mechanism is only at work if the steady state cutoff point for idiosyncratic productivity is at an upward sloping part of the density function. We provide an independent theoretical condition for why this should be the case. In order to obtain a realistic ex-post estimated elasticity of the job-finding rate with respect to market tightness in the model, we also require the cutoff point to be at an upward sloping part of the density function. Based on a survey of matching function estimations, Petrongolo and Pissarides (2001) consider a weight on vacancies in the matching function of 0.5 as an upper bound. ${ }^{5}$ Kohlbrecher et al. (2014) show that including id-

and Merkl (forthcoming) and Lechthaler et al. (2010).

${ }^{4}$ Based on a representative establishment survey for Germany, Hochmuth et al. (2016) show that labor selection is an important adjustment margin over the business cycle. To the best of our knowledge, a comparable dataset is not available for the United States.

${ }^{5}$ Our own estimations, which are available on request, confirm this. 
iosyncratic productivity for match formation in an otherwise standard search and matching model increases the elasticity of matches with respect to vacancies and hence the coefficient in an estimated matching function. The size of this effect depends on the position of the cutoff point for idiosyncratic productivity. A weight on vacancies smaller than 0.5 is only possible if the cutoff point is located to the left of the peak of idiosyncratic productivity. Thus, by targeting a data consistent elasticity of matches with respect to vacancies, our model generates the observed nonlinearities and the shift of the matching efficiency in recessions.

Can the observed patterns in the data also be explained by a standard search and matching model without a labor selection mechanism? Abbritti and Fahr (2013) show that a search and matching model with downward real wage rigidity can indeed generate an asymmetric labor market reaction. Petrosky-Nadeau and Zhang (2013) show that a search and matching model with a Hagedorn and Manovskii (2008) type calibration exhibits labor market asymmetries. Both propositions rely on some form of wage rigidity over the business cycle (although moderate in the latter case). The labor selection mechanism can generate asymmetries of the job-finding rate without resorting to wage rigidity. ${ }^{6}$ Thus, we provide a complementary mechanism, which can strengthen the inherent ability of the search and matching model with wage rigidity to generate asymmetric labor market responses. In addition, the labor selection part generates endogenous shifts of the measured matching efficiency. By contrast, a standard search and matching model without labor selection operates at the time-invariant matching function. Explaining the patterns of the matching efficiency in the data would either require exogenous matching efficiency shocks with a specific correlation to the business cycle or heterogeneity in submarkets. However, based on microeconomic data, Şahin et al. (2014) show that mismatch plays only a moderate role during the Great Recession. Thus, our approach provides an additional explanation for the observed drop of the matching efficiency in deep recessions.

We argue that it is crucial to understand the driving forces of the described labor market nonlinearities. Our model framework generates a time varying effectiveness of certain policy interventions. We illustrate this by implementing a wage subsidy in a recession and in a boom. ${ }^{7}$ In the fully nonlinear model, the wage subsidy is several times more effective in a recession than in a boom in terms of the effect on unemployment. Obviously, this is only a positive statement and not a normative one, which we leave

\footnotetext{
${ }^{6}$ The debate on the degree of wage rigidity is still unresolved. Haefke et al. (2013)'s results point at best to moderate wage rigidity. However, their statistical error bands are relatively large.

${ }^{7}$ The American Recovery and Investment Act contained some elements of this sort, e.g. California's "Jobs Now Program". The Earned Income Tax Credit can also be considered as a wage subsidy.
} 
for future research.

Interestingly, the time-varying policy effectiveness would be true for any policy that affects the present value of workers. This would for example be the case for government spending in a larger-scale model with labor selection. The latter is in line with empirical results from Auerbach and Gorodnichenko (2012).

The rest of the paper is structured as follows. Section 2 presents stylized facts on business cycle asymmetries and the cyclicality of the measured matching efficiency. Section 3 shows a search and matching model with labor selection. Section 4 provides analytical results. Section 5 outlays our calibration strategy and Section 6 presents numerical results in the fully nonlinear setting. Section 7 puts our results in perspective to the existing literature.

\section{Stylized Facts}

This section complements the existing literature on business cycle and labor market asymmetries by some new stylized facts, with particular emphasis on the nonlinear shape of the Beveridge curve and the matching function. It is well known that unemployment behaves asymmetrically over the business cycle (Abbritti and Fahr, 2013; McKay and Reis, 2008). Figure 1 shows annual output and unemployment growth rates for quarterly time series from 1952:I to 2013:II for the United States (see Appendix A for a data description). The unemployment rate moves a lot more in recessions than in booms. ${ }^{8}$ The skewness of unemployment may appear unsurprising because the standard unemployment equation is highly nonlinear. ${ }^{9}$

However, Figure 2 illustrates that the job-finding rate is also strongly skewed, although in the opposite direction as unemployment. The job-finding rate falls a lot more in recessions than it increases in booms. ${ }^{10}$ Thus, the strong decline of the job-finding rate in recessions is an important driver for the asymmetric increase of the unemployment rate as also shown by Ferraro $(2016) \cdot{ }^{11}$

\footnotetext{
${ }^{8}$ This is both true for the unemployment level and the unemployment rate. The unemployment rate is also skewed when absolute instead of percent deviations are taken.

${ }^{9}$ Consider the steady state unemployment rate $u=\frac{s r}{j f r+s r}$, where $s r$ is the separation rate and $j f r$ is the job-finding rate. Even with a symmetric job-finding rate, unemployment would be skewed. This can be seen by taking the second derivative with respect to the job-finding rate: $\frac{\partial^{2} u}{\partial j f r^{2}}>0$.

${ }^{10}$ The skewness of the job-finding rate time series becomes even more pronounced when looking at absolute instead of percent deviations.

${ }^{11}$ Ferraro (2016) argues that the skewed separation rate based on Shimer (2012)'s dataset is an equally important driver for the skewness of unemployment. However, in the JOLTS dataset (which only covers the period after the year 2000) the spike of layoffs in the Great Recession was completely compensated by the decline of quits (i.e. there was no spike of overall separations). It is unclear to us whether the compensating effects of quits are peculiar to the Great Recession or a general phenomenon, which is not visible in other
} 


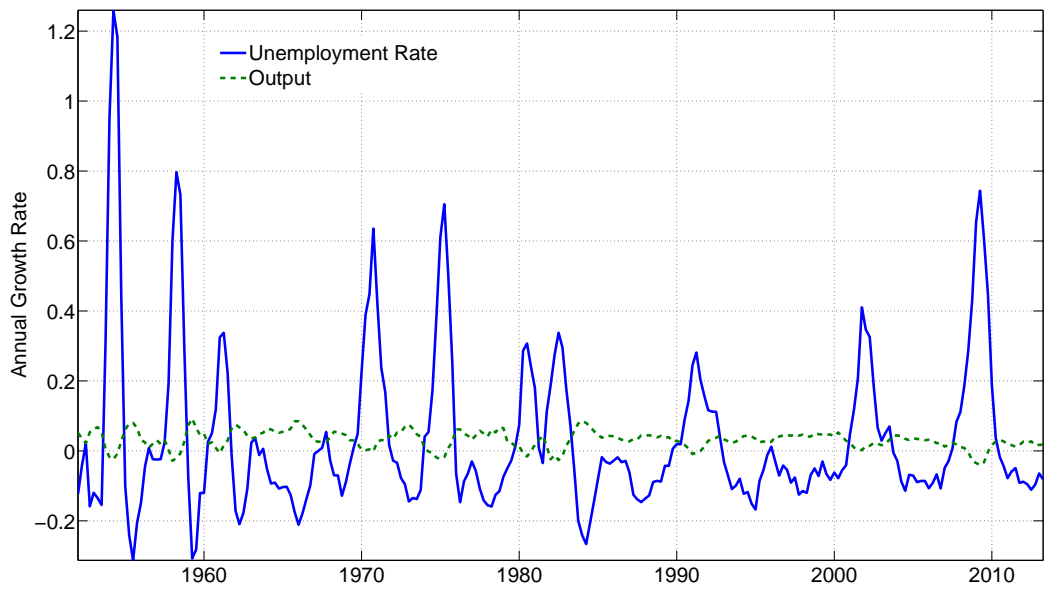

Figure 1: Annual growth rates of unemployment rate and real GDP.

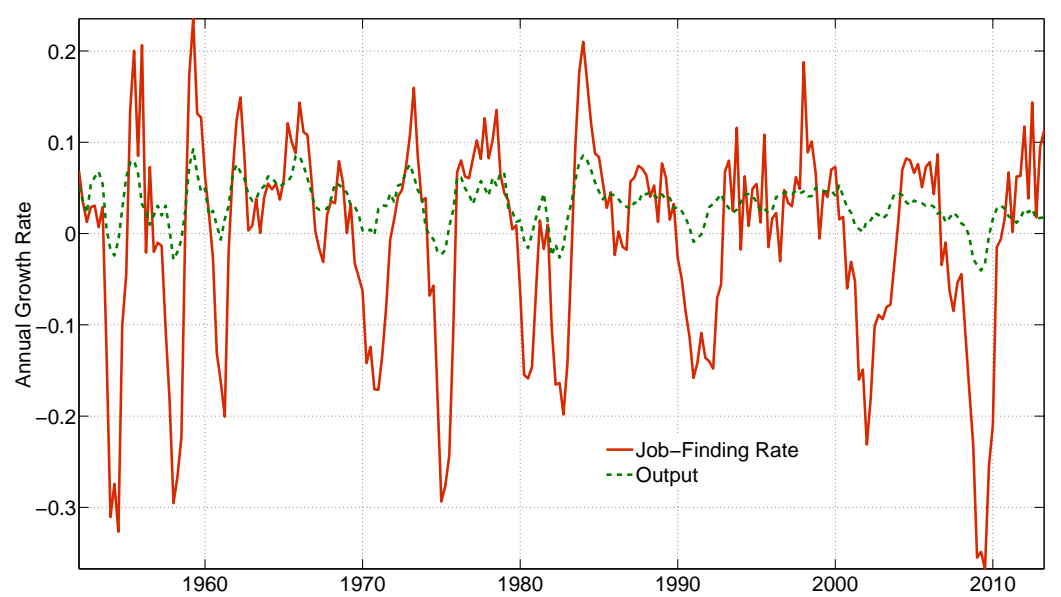

Figure 2: Annual growth rates of job-finding rate and real GDP. 
Interestingly, the annual growth rates of vacancies and market tightness in Figure 3 do not show asymmetries. Table B.2 in the Appendix confirms that - in contrast to the other labor market variables - vacancies and market tightness have a low level of skewness, which is not statistically significantly different from zero. This fact is not stressed in the existing literature on business cycle asymmetries, but has important consequences for the nonlinearities of the matching function and the Beveridge curve. It is also worth emphasizing that due to the large relative fluctuations of market tightness and vacancies, it is particularly important to calculate the actual growth rates and not to rely on a log-approximation. The latter generates an artificial downward skewness due to a large approximation error (see Appendix B.2 for details).

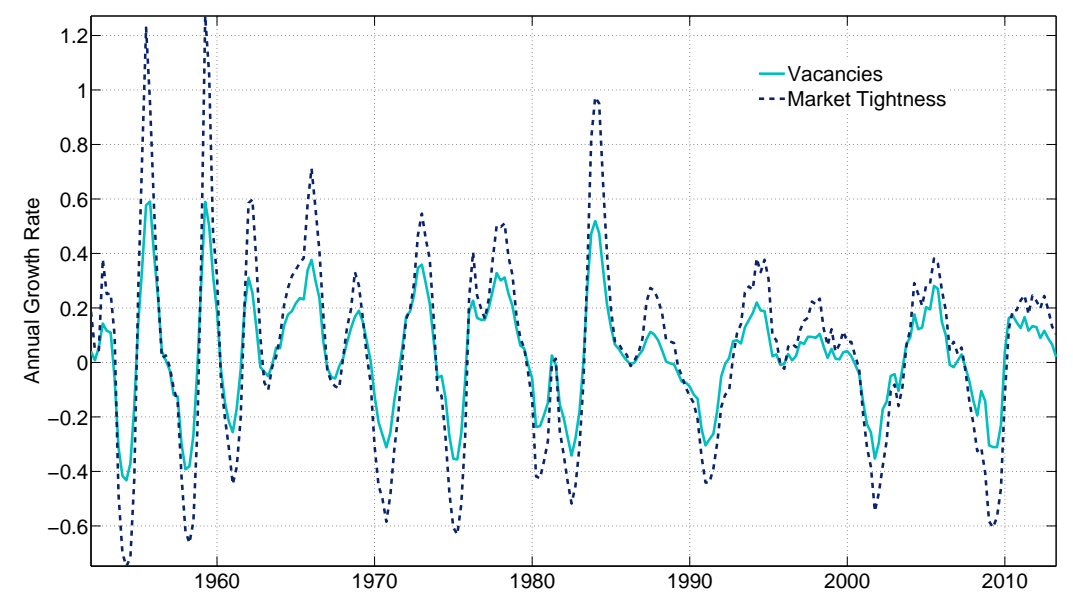

Figure 3: Annual growth rates of vacancies and market tightness.

Another way of looking at these facts is to split the sample in periods when annual output growth is above and below median. Table 1 shows the standard deviation of the annual growth rates of different labor market variables for the respective periods.

Interestingly, the job-finding rate and unemployment move a lot more during downswings than during upswings. The standard deviation of the job-finding rate and unemployment increases roughly by factor two and four respectively during downswings. By contrast, the standard deviation of vacancies and market tightness is barely affected by the business cycle. ${ }^{12}$

datasets that are unable to disentangle layoffs and quits. We leave this for future research and focus on the role of job creation in this paper. Given that Ferraro (2016) shows that the participation rate is not skewed, we do not analyze this margin.

${ }^{12}$ The results are robust when we split the data in four quantiles for output growth 


\begin{tabular}{llllll}
\hline Variable & $U$ & $J F R$ & $V$ & $\theta$ & $Y$ \\
\hline Output Growth Below Median & 0.27 & 0.11 & 0.16 & 0.28 & 0.02 \\
\hline Output Growth Above Median & 0.07 & 0.06 & 0.15 & 0.27 & 0.01
\end{tabular}

Table 1: Standard deviations of different labor market variables during periods when the output growth is below and above median. Statistics are based on yearto-year growth rates for quarterly US data from 1952:I to 2013:II.

The combination of all these facts allows for an interesting perspective on the Beveridge curve and the matching function.

Stylized Fact 1. The Beveridge curve shows strong nonlinearities. We provide two perspectives: First, in recessions the dynamic adjustment path of the Beveridge curve shows an outward shift (Diamond and Şahin, 2014). However, there is no clear pattern in booms. Second, based on annual growth rates, the Beveridge curve becomes very nonlinear for large positive growth rates of unemployment.

Figure 4 shows the dynamic adjustment during US post-war recessions in the vacancy-unemployment space. Given that we only look at a short time horizon, we do not apply any business cycle filter. The green star is the maximum unemployment rate, the red dot denotes the vacancy-unemployment combination four quarters before and the turquois cross denotes the position four quarters after the maximum unemployment rate. This Figure is a replication of Diamond and Şahin (2014) who emphasize that the Beveridge curve has shifted outward in eight out of nine recessions.

We complement the work of Diamond and Şahin (2014) by showing the dynamic adjustment path for booms, where the green star denotes the minimum unemployment rate and the red dot (turquois cross) denotes the position four quarters before (afterwards). Interestingly, in contrast to the consistent outward shift of the Beveridge curve in most recessions, there is no clear pattern in booms. Thus, the dynamic adjustment path of the Beveridge curve in recessions and in booms is clearly asymmetric.

Christiano et al. (2015) argue that the outward shift of the Beveridge curve can be explained by the dynamic adjustment path of the search and matching model, which is missed when using a steady state approximation for unemployment. However, in a linear or linearized model with symmetric shocks, we should expect the same dynamic outward/inward shifts in recessions and booms respectively. Figures 4 and 5 show that this is clearly not the case.

Another way of illustrating the nonlinearities of the Beveridge curve is to depict the annual growth rates in the vacancy-unemployment-space. Figure

instead. The fluctuations of the job-finding rate and unemployment are the largest when output growth is below the $25 \%$ threshold. 

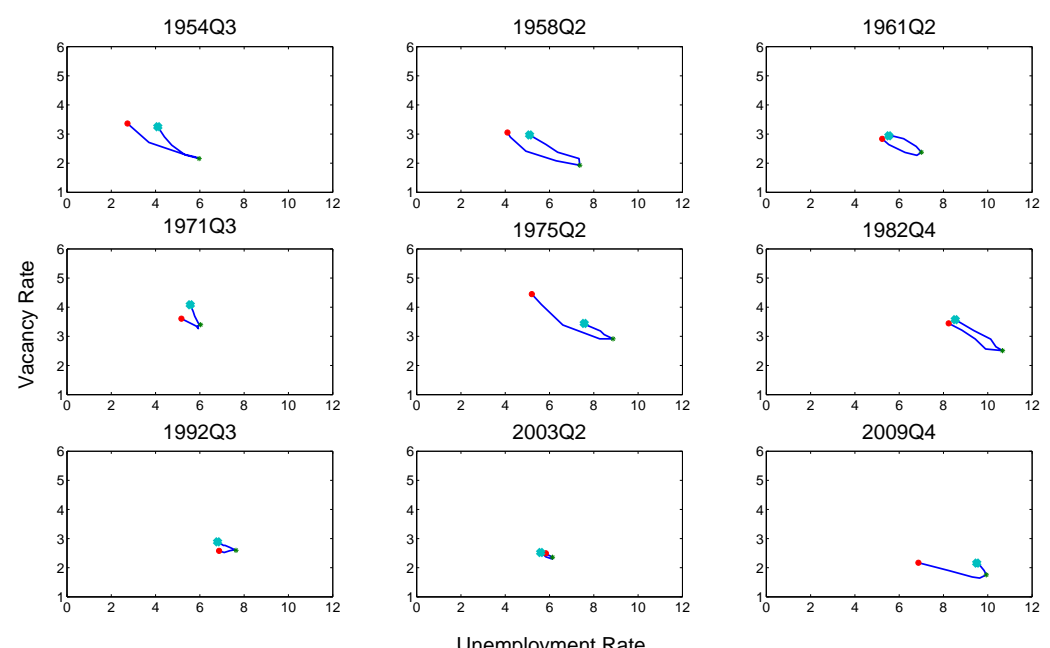

Figure 4: The US Beveridge curve in recessions. Peak of the unemployment rate $+/-$ four quarters.
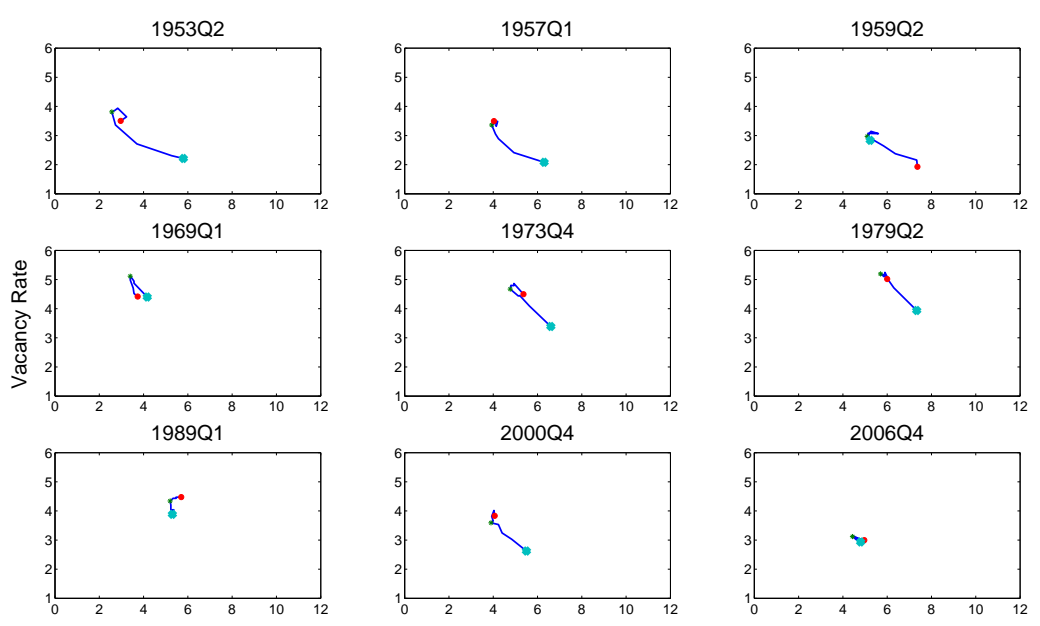

Figure 5: The US Beveridge curve in booms. Trough of the unemployment rate $+/-$ four quarters. 
6 shows that the Beveridge curve becomes particularly nonlinear with large unemployment increases. This is the flip side of the observations above that unemployment is very skewed over the business cycle, while vacancies show a symmetric pattern.

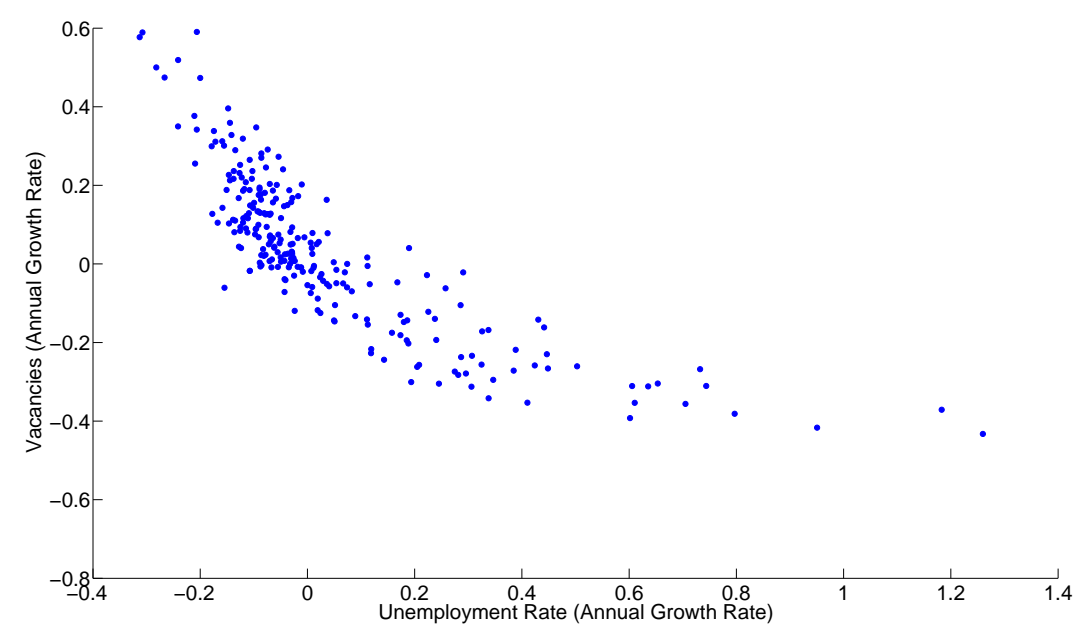

Figure 6: The US Beveridge curve (1952-2013).

Stylized Fact 2. The matching function is very nonlinear. For large market tightness growth rates (both negative and positive), the growth rate of the jobfinding rate is consistently below its predicted value.

Figure 7 depicts the annual gross growth rate of the job-finding rate and market tightness. For illustration purposes, we add predictions based on a linear and a nonlinear Cobb-Douglas constant returns matching function to the figure. ${ }^{13}$

It is clearly visible that the linear matching function is particularly inadequate in times of severe market tightness upswings or downswings. The nonlinear matching function provides a much better fit. However, even the nonlinear version has trouble fitting the extremes, where it systematically overpredicts the job-finding rate. For large upswings and downswings of market tightness, most of the predicted values for the job-finding rate are above the actual realizations. The systematic difference between the job-finding rate and its predicted value suggests a decline of the matching efficiency in severe recessions if one looks at the data through the lens of a standard matching function. This is connected to the recent debate on the decline of

\footnotetext{
${ }^{13}$ The linear matching function prediction is based on $j \hat{f} r_{t}=\hat{\alpha}_{1}+\hat{\alpha}_{2} \theta_{t}$ and the nonlinear one on $j \hat{f} r_{t}=\hat{\alpha}_{3} \theta_{t}^{\hat{\alpha}_{4}}$. The $\hat{\alpha}$ 's are picked to minimize the sum of the squared error terms, which is obviously much smaller under the nonlinear fit.
} 


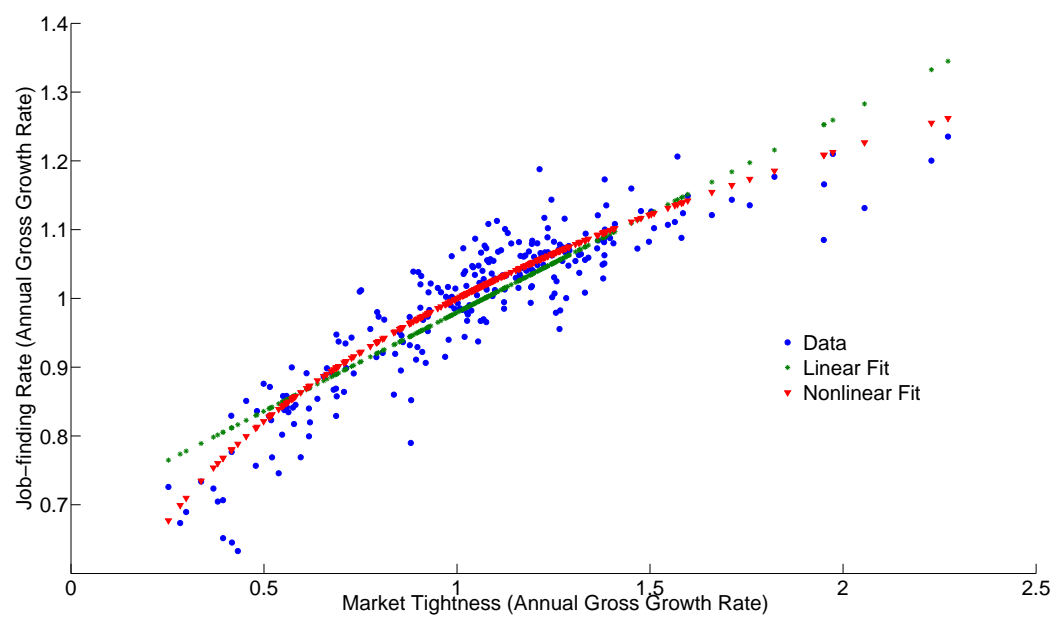

Figure 7: The US matching function (1952-2013).

the matching efficiency in the Great Recession (see e.g. Gavazza et al., 2015; Barnichon and Figura, 2015; Lubik, 2013).

This section has collected stylized facts from the literature and complemented them with some new insights and perspective. We will show next that enhancing a search and matching model with a labor selection mechanism can explain all these facts.

\section{The Model}

We use a version of the Diamond-Mortensen-Pissarides (DMP) model (e.g. Mortensen and Pissarides, 1994) in discrete time and enrich it with one simple mechanism: idiosyncratic productivity for newly created jobs.

There is a continuum of workers on the unit interval who can either be employed or unemployed. Unemployed workers search for jobs and receive unemployment compensation $b$, employed workers can lose their job with constant probability $\phi$. Firms have to post vacancies in order to get in contact with a worker and pay vacancy posting costs $\kappa$ per vacancy. We assume free-entry of vacancies. Contacts between searching workers and firms are established via a standard Cobb-Douglas contact function. In contrast to the basic search and matching model, not every contact between vacancies and workers ends in a hire. Upon contact, firms and workers draw from an idiosyncratic productivity distribution determining the match specific productivity, $\varepsilon_{i t}$, for the first period of production. Only contacts that are productive enough, $\varepsilon_{i t} \geq \tilde{\varepsilon}_{t}$, will result in a job, where $\tilde{\varepsilon}_{t}$ is the cutoff productivity that makes a firm indifferent between hiring and not hiring a 
worker. Our model is the same as in Kohlbrecher et al. (2014) and similar to the stochastic job matching model (Pissarides, 2000, chapter 6) or many of the endogenous separation models (e.g. Krause and Lubik, 2007). Brown et al. (2015) and Lechthaler et al. (2010) are examples of labor selection models with idiosyncratic productivity (but without contact function). Our model is different from the latter in assuming that only new hires vary in their productivity. We choose this simplifying assumption to emphasize the role of idiosyncratic shocks for match formation.

\subsection{Contacts}

Contacts between searching workers and firms are established via a CobbDouglas, constant returns to scale (CRS) contact function,

$$
c_{t}=\mu v_{t}^{\gamma} u_{t}^{1-\gamma},
$$

where $u_{t}$ and $v_{t}$ are the beginning of period $t$ unemployment and vacancy stocks, $\mu$ is the contact efficiency and $c_{t}$ is the overall number of contacts in period $t$. We define the contact probability for a worker as

$$
p_{t}=\mu \theta_{t}^{\gamma}
$$

and the contact probability for a firm as

$$
q_{t}=\mu \theta_{t}^{\gamma-1},
$$

with $\theta_{t}=v_{t} / u_{t}$.

\subsection{The Selection Decision}

Upon contact, firm and worker gain information about their match specific productivity at the start of the match. Technically, they draw a shock, $\varepsilon_{i t}$, from an idiosyncratic productivity distribution, which is iid across workers and time, with density $f(\varepsilon)$ and cumulative distribution $F(\varepsilon) .{ }^{14}$ The expected discounted profit of a firm hiring a new worker (denoted with superscript $E$ for entrant) with match-specific productivity $\varepsilon_{t}$ is given by

$$
\pi_{t}^{E}\left(\varepsilon_{t}\right)=a_{t}+\varepsilon_{t}-w_{t}^{E}\left(\varepsilon_{t}\right)+\delta(1-\phi) E_{t}\left(\pi_{t+1}^{I}\right),
$$

where $a_{t}$ is the aggregate productivity in the economy at time $t, w_{t}\left(\varepsilon_{t}\right)$ is the match specific wage, $\delta$ is the discount factor, and $\pi_{t}^{I}$ is the expected discounted profit of an existing match (denoted with superscript $I$ for incumbent). Existing matches are not subject to shocks and thus all produce with the same productivity. The profits are thus given by:

\footnotetext{
${ }^{14}$ Due to the iid assumption, we abstract from the worker-firm pair specific index $i$ from here onward.
} 


$$
\pi_{t}^{I}=a_{t}-w_{t}^{I}+\delta(1-\phi) E_{t}\left(\pi_{t+1}^{I}\right)
$$

A firm will hire a worker whenever the expected discounted profit is positive. The cutoff productivity that makes a firm indifferent between hiring and not hiring the worker is thus

$$
\tilde{\varepsilon}_{t}=w_{t}^{E}\left(\varepsilon_{t}\right)-a_{t}-\delta(1-\phi) E_{t}\left(\pi_{t+1}^{I}\right) .
$$

The ex-ante probability that a contact is selected into a job is thus

$$
\eta_{t}=\int_{\tilde{\varepsilon}_{t}}^{\infty} f\left(\varepsilon_{t}\right) d \varepsilon_{t}
$$

\subsection{Vacancies}

In order to make a contact, firms have to post vacancies and pay vacancy posting costs $\kappa$. The value of a vacancy is

$$
\Psi_{t}=-\kappa+q_{t} \eta_{t} E_{t}\left[\pi_{t}^{E} \mid \varepsilon_{t} \geq \tilde{\varepsilon}_{t}\right]+\left(1-q_{t} \eta_{t}\right) \Psi_{t+1},
$$

where $q_{t} \eta_{t}$ is the overall probability that a vacancy leads to a productive match. We assume free entry for vacancies such that the value of a vacancy will be driven to zero. The vacancy condition thus simplifies to

$$
\begin{aligned}
\frac{\kappa}{q_{t} \eta_{t}} & =E_{t}\left[\pi_{t}^{E} \mid \varepsilon_{t} \geq \tilde{\varepsilon}_{t}\right] \\
& =a_{t}+\frac{\int_{\tilde{\varepsilon}_{t}}^{\infty}\left(\varepsilon_{t}-w_{t}^{E}\left(\varepsilon_{t}\right)\right) f\left(\varepsilon_{t}\right) d \varepsilon_{t}}{\eta_{t}}+\delta(1-\phi) E_{t}\left(\pi_{t+1}^{I}\right) .
\end{aligned}
$$

\subsection{Wages}

We assume Nash bargaining for both new and existing matches. Workers have linear utility over consumption. Let $V_{t}^{U}, V_{t}^{E}$, and $V_{t}^{I}$ denote the value of unemployment, the value of a job for an entrant worker and the value of a job for an incumbent worker.

$$
\begin{gathered}
V_{t}^{U}=b+\delta E_{t}\left(p_{t+1} \eta_{t+1} V_{t+1}^{E}\left[\varepsilon_{t+1} \geq \tilde{\varepsilon}_{t+1}\right]+\left(1-p_{t+1} \eta_{t+1}\right) V_{t+1}^{U}\right) \\
V_{t}^{E}\left(\varepsilon_{t}\right)=w_{t}^{E}\left(\varepsilon_{t}\right)+\delta E_{t}\left((1-\phi) V_{t+1}^{I}+\phi V_{t+1}^{U}\right) \\
V_{t}^{I}=w_{t}^{I}+\delta E_{t}\left((1-\phi) V_{t+1}^{I}+\phi V_{t+1}^{U}\right) .
\end{gathered}
$$

The wage for an entrant and the wage for an incumbent worker are thus determined by the following maximization problems: 


$$
\begin{gathered}
w_{t}^{E}\left(\varepsilon_{t}\right) \in \arg \max \left(V_{t}^{E}\left(\varepsilon_{t}\right)-V_{t}^{U}\right)^{\alpha}\left(\pi_{t}^{E}\left(\varepsilon_{t}\right)\right)^{1-\alpha}, \\
w_{t}^{I} \in \arg \max \left(V_{t}^{I}-V_{t}^{U}\right)^{\alpha}\left(\pi_{t}^{I}\right)^{1-\alpha} .
\end{gathered}
$$

\subsection{Employment}

The law of motion for employment is

$$
n_{t+1}=(1-\phi) n_{t}+p_{t} \eta_{t} u_{t}
$$

with

$$
u_{t}=1-n_{t}
$$

\subsection{Labor market equilibrium}

Given an initial condition for employment $n_{0}$ and a stochastic process for technology $\left\{a_{t}\right\}_{t=0}^{+\infty}$, the labor market equilibrium is a sequence of allocations $\left\{u_{t+1}, n_{t+1}, p_{t}, q_{t}, \pi_{t}, \eta_{t}, v_{t}, \tilde{\varepsilon}_{t}, w_{t}^{I}, w_{t}^{E}\right\}_{t=0}^{+\infty}$ satisfying equations (2), (3), (5), (6), (7), (9), (13), (14), the law of motion for employment (15), and the definition of unemployment (16).

\section{Analytical Results}

This section demonstrates that idiosyncratic shocks for new contacts in the search and matching model generate important asymmetries. To highlight the effect of the selection mechanism, we derive analytical results based on the steady state version of a pure selection model. More precisely, we assume that the contact rate is constant by setting $\gamma=0$. In this case, the job-finding rate is only driven by selection. We prove analytically that the pure selection model can generate asymmetries of the job-finding rate and unemployment. This is also true when wages (for a specific idiosyncratic realization) comove one to one with aggregate productivity. In addition, we show that matching efficiency, if seen through the lens of a standard search and matching model, declines under negative productivity shocks.

The Appendix also contains derivations for the opposite polar case, namely a search and matching model without labor selection. It shows that the steady state version of the search and matching model can only generate asymmetries with some form of wage rigidity. Obviously, the standard search and matching model cannot generate any endogenous shifts of the matching efficiency.

To set the stage and to provide some intuition, consider the model dynamics of a pure selection model. Both the job-finding rate and market 
tightness move in response to a productivity shock in this model. Assume a positive productivity shift: The selection rate and hence the job-finding rate increase because it becomes profitable for firms to select workers with lower idiosyncratic productivity. In addition, firms post more vacancies as larger aggregate productivity increases the ex-ante expected profits. Hence, vacancies and thereby market tightness go up. ${ }^{15}$ Kohlbrecher et al. (2014) show that this positive comovement is observationally equivalent to a constant returns Cobb-Douglas matching function - even with a constant contact rate, $\gamma=0$. If simulated data from the model is used to estimate a standard CobbDouglas matching function, the estimated weight on vacancies corresponds to the elasticity of the job-finding rate with respect to market tightness in the model. In the steady state version of the pure selection model, this elasticity is given by the following expression:

$$
\frac{\partial \ln \eta}{\partial \ln \theta}=\frac{\partial \frac{\int_{\tilde{\varepsilon}}^{\infty} \varepsilon f(\varepsilon) d \varepsilon}{\eta}}{\partial \tilde{\varepsilon}}=\frac{f(\tilde{\varepsilon})}{\eta}\left(\frac{\int_{\tilde{\varepsilon}}^{\infty} \varepsilon f(\varepsilon) d \varepsilon}{\eta}-\tilde{\varepsilon}\right) .
$$

This expression depends only on the distribution of idiosyncratic productivity and the position of the hiring cutoff point in that distribution. Technically, the elasticity is equal to the first derivative of the conditional expectation of the idiosyncratic productivity shock with respect to the cutoff point $\tilde{\varepsilon}$ (see Appendix for details). Figure 8 illustrates this point. The upper panel shows three common density functions for idiosyncratic productivity. The lower panel shows the corresponding elasticity of the job-finding rate with respect to market tightness at different cutoff points based on equation (17).

Against this background, we derive two results that are helpful for a better understanding of the numerical results in Section 6 .

Result 1. If the probability density function of idiosyncratic productivity is upward sloping at the cutoff point, the job-finding rate reacts more in recessions than in booms. $\frac{\partial^{2} \eta}{\partial a^{2}}<0$ if $f^{\prime}(\tilde{\varepsilon})>0$.

For the analytical proof see Appendix C.2.1.

Intuition. A negative (positive) aggregate productivity change moves the cutoff point to a part of the density function with more (less) density. This generates asymmetric responses of the job-finding rate.

Result 2. With $f^{\prime}(\tilde{\varepsilon})>0$, a negative productivity shock generates a fall of the measured matching efficiency.

See Appendix C.2.2 for details.

\footnotetext{
${ }^{15}$ Given that the contact function is degenerate, in aggregate more vacancies do not lead to more contacts. However, firms have an incentive to post vacancies up to the point where the expected profits are zero.
} 


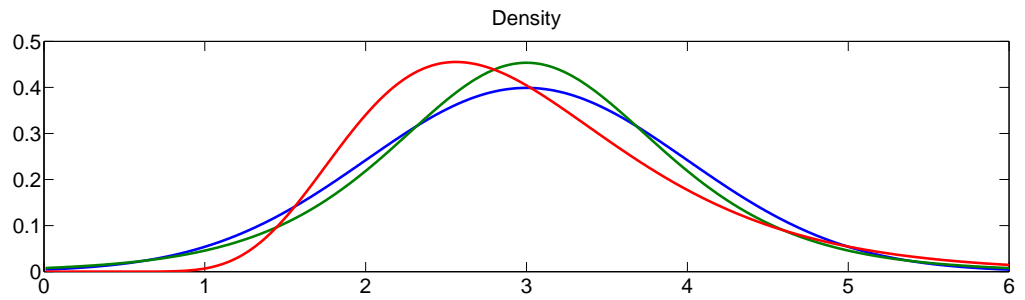

First Derivative of Conditional Expectation

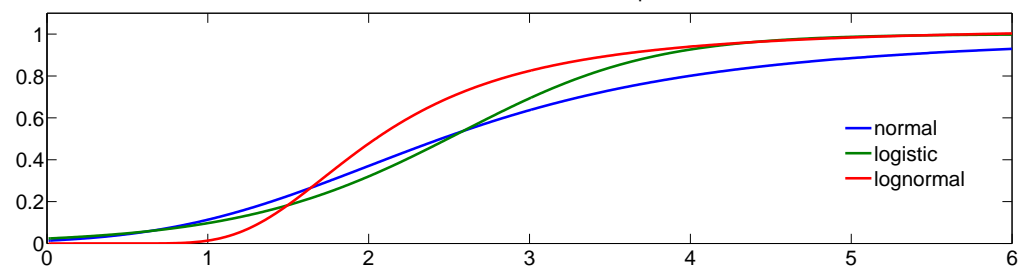

Figure 8: Predicted matching coefficients for standard distributions. Density function (upper panel) and first derivative of conditional expectation (lower panel) for different standard distributions (normal, logistic, and lognormal). For comparability reasons, the variance is normalized to 1 and the mean is set to 3 .

Intuition. It follows from result 1 that the job-finding rate reacts more in a recession than in a boom. In addition, firms anticipate that they will hire workers with on average larger idiosyncratic productivity in a recession. Due to this composition effect, the reduction in vacancy posting is smaller. Thus, the job-finding rate falls very strongly in a recession, while the decline of market tightness is muted. Through the lens of a matching function, this leads to a drop of the measured matching efficiency and to an outward shift of the Beveridge curve in a recession.

To illustrate this further, take Figure 8 and assume that the steady state cutoff point is at value 2. Assume an equal upward and downward shift of aggregate productivity, which leads to a symmetric movement of the cutoff point (e.g. from 2 to 1.5 and 2.5 in the boom and recession respectively). ${ }^{16}$ During the boom, the selection rate changes by a lot less than during the recession due to the curvature of the density function (upper panel). In addition, the comovement between the job-finding rate and market tightness changes (lower panel). For a certain downward movement of market tightness, the job-finding rate falls by more than expected. This manifests itself in a drop of the measured matching efficiency if the weight on vacancies is assumed to be a fixed number.

We require $f^{\prime}(\tilde{\varepsilon})>0$ in order to generate nonlinearities of the job-finding

\footnotetext{
${ }^{16}$ We prove in the Appendix that symmetric productivity movements generate symmetric cutoff movements: $\frac{\partial^{2} \tilde{\varepsilon}}{\partial a^{2}}=0$.
} 
rate and a drop of the measured matching efficiency in recessions. With a uniform distribution, $f^{\prime}(\tilde{\varepsilon})=0$, the job-finding rate shows no asymmetries and with $f^{\prime}(\tilde{\varepsilon})>0$, the asymmetries of the job-finding rate would move in the wrong direction.

Why should $f^{\prime}(\tilde{\varepsilon})>0$ be a plausible condition? We have shown that the position of the cutoff point determines the weight on vacancies in an estimated matching function (see equation (17)). Figure 8 illustrates that a weight on vacancies smaller than 0.5 (lower panel) is only possible in an upward sloping part of the density function.

Let us compare this with the results from existing matching function estimations. The survey by Petrongolo and Pissarides (2001) considers a weight on vacancies of 0.5 as an upper bound in a broad range of estimations. We have also estimated matching functions for the United States based on the long time series for the job-finding rate and market tightness. Independent of the filtering/detrending (none, HP-filter, fourth differences, linear trend), the estimated weight on vacancies is always smaller than $0.5 .^{17}$ The bottom line is that in order to obtain a realistic estimated matching function in a selection model (with weight on vacancies smaller than 0.5 ), we require $f^{\prime}(\tilde{\varepsilon})>0$. This provides a theoretical external validity condition for our model mechanism.

An important question is how this result changes when we move to the more realistic case with a standard contact function $(\gamma>0)$, which we will do in our numerical simulations. Kohlbrecher et al. (2014) show that a weight on vacancies above zero in the contact function adds to the weight on vacancies in the estimated matching function. ${ }^{18}$ Thus, if both mechanisms are at work (contact and selection), the steady state cutoff point even has to be further to the left in Figure 8 to obtain a weight on vacancies smaller than 0.5.

So far, we have illustrated that the labor selection mechanism (idiosyncratic shocks for new contacts) can generate asymmetries of the job-finding rate and a decline of the measured matching efficiency in recessions. In our numerical part below, we will use the full model where both search and matching and labor selection are at work. Furthermore, we will show that the generated asymmetries are quantitatively meaningful.

\section{Calibration}

We calibrate the model to a monthly frequency and then aggregate to obtain quarterly series. We target a steady state job-finding rate, $p \cdot \eta$, of 0.45 as in

\footnotetext{
${ }^{17}$ Results are available on request.

${ }^{18}$ We can show numerically that the weight on vacancies due to contact and selection are approximately additive. When estimating, $j f r_{t}=\beta_{o}+\beta_{1} \theta_{t}+\varepsilon_{t}$, the estimated coefficient would approximately correspond to $\hat{\beta}_{1} \approx \gamma+\frac{\partial \frac{\partial \int_{\tilde{\varepsilon}}^{\infty} \varepsilon f(\varepsilon) d \varepsilon}{\eta}}{\partial \tilde{\varepsilon}}$
} 
Shimer (2005) and set the separation rate to 3\% per month. Market tightness is normalized to one. As in Shimer (2005) we set the bargaining power of workers to $\alpha=0.28$. The discount factor is $\delta=0.99^{1 / 3}$. Unemployment compensation is $70 \%$ of steady state productivity. This is an intermediate value between those used in Shimer (2005) and Hagedorn and Manovskii (2008).

As both the selection mechanism and the contact function affect the elasticity of the job-finding rate with respect to market tightness, it is no longer clear how big the coefficient on vacancies in the contact function, $\gamma$, should be. Kohlbrecher et al. (2014) use data on individual entry wages for Germany to determine the relative contribution of the selection mechanism and the contact function to the overall elasticity of the job-finding rate with respect to market tightness. They find that the larger part of the comovement between these variables is driven by selection. When we fit a Cobb-Douglas constant returns nonlinear matching function to the data in Section 2, we obtain a coefficient on vacancies of about 0.3 , which is well in line with existing evidence on matching function estimations (see e.g. Petrongolo and Pissarides, 2001; Shimer, 2005). ${ }^{19}$ We therefore set the coefficient on vacancies in the contact function to $\gamma=0.1$, i.e. we assume that around one third of the elasticity is driven by the contact margin. Note, however, that we have experimented with several combinations of $\gamma$. Our qualitative results are unaffected by this.

We assume a normal distribution for our match specific shocks. We determine the parameters of the normal distribution to meet two targets from the data: An estimated matching function coefficient of 0.3 and the relative volatility of the job-finding rate with respect to productivity in the data, which is $5.4 .^{20}$ Intuitively, the first target determines the position of the cutoff point in the distribution (see Figure 8). Given the target, it immediately follows that the cutoff point will be in the upward sloping part of the distribution. The second target determines how much mass there will be in the vicinity of the cutoff point and hence pins down the dispersion of the distribution. In our paper, we do not want to discuss the ability of the selection mechanism to generate amplification. ${ }^{21}$ By contrast, we want to analyze the business cycle properties of a search and matching model with a realistically volatile job-finding rate in order to analyze the nonlinear behavior of the model in severe recessions. An alternative strategy would be to choose a more dispersed idiosyncratic productivity shock and to use different shocks (e.g. discount factor or preference shocks) or to introduce additional model mechanisms in order to generate large fluctuations of the

\footnotetext{
${ }^{19}$ The coefficient is 0.29 for a linear estimation and 0.28 for the nonlinear estimation based on annual growth rates.

${ }^{20}$ Both in terms of the annual growth rate.

${ }^{21}$ See Chugh and Merkl (forthcoming) for a discussion of the ability of selection models to generate amplification.
} 
job-finding rate.

Given the targets for the weight on vacancies in the matching function and the relative volatility of the job-finding rate, the standard deviation of our distribution is 0.09 . The steady state selection rate is 0.96 and the steady state contact rate is 0.47 .

Finally, with steady state market tightness equal to one, we obtain a contact efficiency $\mu=0.47$. Finally, we set the vacancy posting cost to satisfy the zero profit condition.

We perform two numerical exercises: First, we look at the nonlinear impulse responses of the economy in response to a large (and persistent) aggregate productivity shock. Second, we solve for the fully nonlinear dynamic path of our model using the Fair and Taylor (1983) shooting algorithm. Instead of drawing from a random shock series, our model simulation is based on the actual time series of labor productivity growth in the data. The advantage of this approach is that our model results reflect the real productivity evolution during our time span and are thus directly comparable to the results in Section 2.

We follow the usual convention in the business cycle asymmetries literature and filter the data in terms of annual growth rates (see e.g. Abbritti and Fahr, 2013). This ensures that we obtain stationary data, as required for our model simulation. The alternative would be to take the logarithm of time series and to HP-filter them. However, as shown in the Appendix this approach has caveats when using variables that exhibit large fluctuations.

Thus, labor productivity - as input into our simulation - is defined as the annual growth rate of gross value added over employment in the nonfarm business sector from the first quarter of 1952 to the second quarter of 2013. We normalize the mean of productivity growth to one. Note that productivity itself is not skewed. ${ }^{22}$ As we simulate on a monthly frequency, we interpolate labor productivity to a monthly frequency using industrial production and the method by Chow and Lin (1971). The simulated data is then aggregated back to quarterly frequency. The standard deviation of our quarterly productivity process (both in the data and in the simulation) is $2.09 \%$ and the autocorrelation is 0.79 .

Note finally, that our calibration results in a reasonable cyclicality of entry wages. A one unit increase in productivity leads on average to a 0.6 unit increase in the mean entry wage. Our wage, however, is completely flexible. For a given idiosyncratic productivity realization, the wage moves nearly one to one with aggregate productivity. The entry wage, however, is subject to a composition effect. If productivity goes up, firms are willing to hire less productive workers, which lowers the average entry wage by some extend.

\footnotetext{
${ }^{22}$ If any, it would be positively skewed. However, the coefficient is very small and not statistically significant.
} 


\section{Results}

\subsection{Inspecting the Mechanism Numerically}

To illustrate the driving forces for business cycle asymmetries and the shift of the matching efficiency, Figure 9 shows the fully nonlinear impulse response functions of the model economy to a $2.5 \%$ positive and a $2.5 \%$ negative productivity shock. These exercises are meant to replicate severe recession and boom scenarios.

Although the aggregate shocks are symmetric, the job-finding rate and the unemployment rate move by roughly 50 percent more in case of the negative aggregate shock compared to the positive shock. Vacancies and market tightness, in contrast, move almost symmetrically.
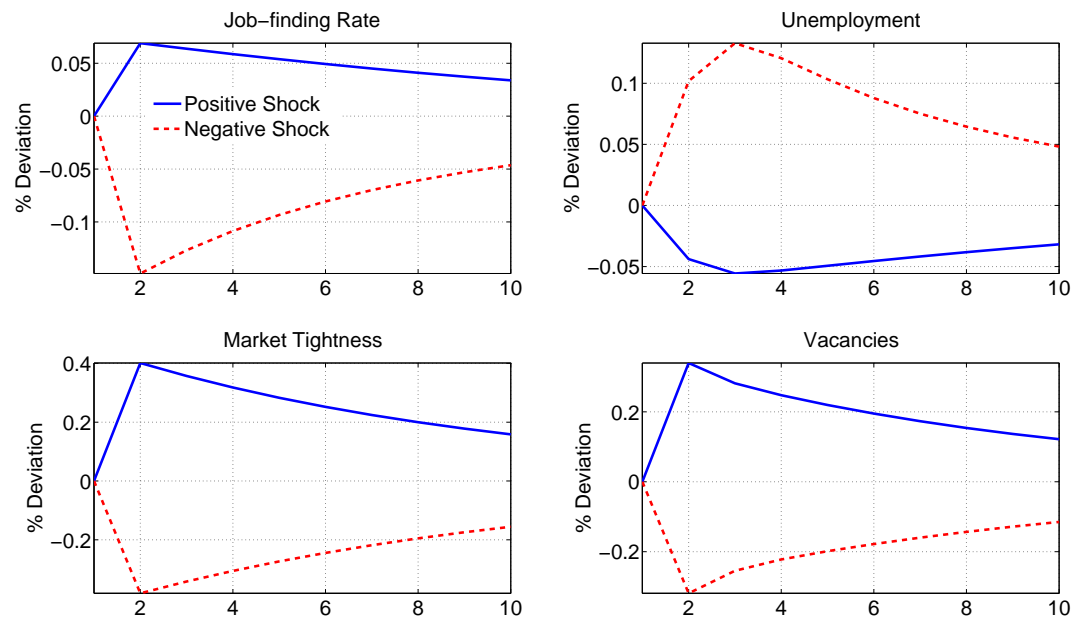

Figure 9: Model impulse responses to positive and negative productivity shock (in percent deviations from steady state).

This exercise illustrates that the nonlinearities generated by the selection part of the model are quantitatively meaningful. Given that the cutoff point is located at an upward sloping part of the density function in steady state (i.e. $f^{\prime}(\tilde{\varepsilon})>0$, see Section 4 for details), a negative aggregate shock moves the selection cutoff point to a part of the idiosyncratic productivity density function with more mass. Thus, a given change of the cutoff point exerts a larger effect on the job-finding rate.

While the job-finding rate falls a lot in a severe recession, the response of market tightness is muted. Firms anticipate in their vacancy posting behavior that they hire workers with on average larger idiosyncratic productivity in a recession compared to a boom. This composition effect mutes the response of vacancies and market tightness to an aggregate productivity shock. 
Through the lens of the matching function, the strong decline of the jobfinding rate and the muted decline of market tightness would be interpreted as a decline of the matching efficiency, i.e. an exogenous deterioration of the efficiency of the labor market. However, through the lens of our model, this decline is simply a result of the severe recession, the labor selection mechanism and the resulting nonlinearities. Once the aggregate shock disappears, the selection rate will return to its steady state level and the measured matching efficiency will recover.

\subsection{Beveridge Curve and Matching Function}

Figure 10 shows the dynamic response of the model economy in response to a $2.5 \%$ positive and negative productivity shock in the unemployment-vacancy space. In our simulation exercise, vacancies move by roughly 35 percent (in absolute terms) both during the boom and during the recession. By contrast, due to the nonlinearities of the model, unemployment moves by about one half more in recessions compared to booms. As in the data, the recession is associated with a strong outward shift of the Beveridge curve. By contrast, the inward shift in the boom scenario is less pronounced. Thus, our model provides an explanation for the differential response of the Beveridge curve in booms and recessions observed in the data.
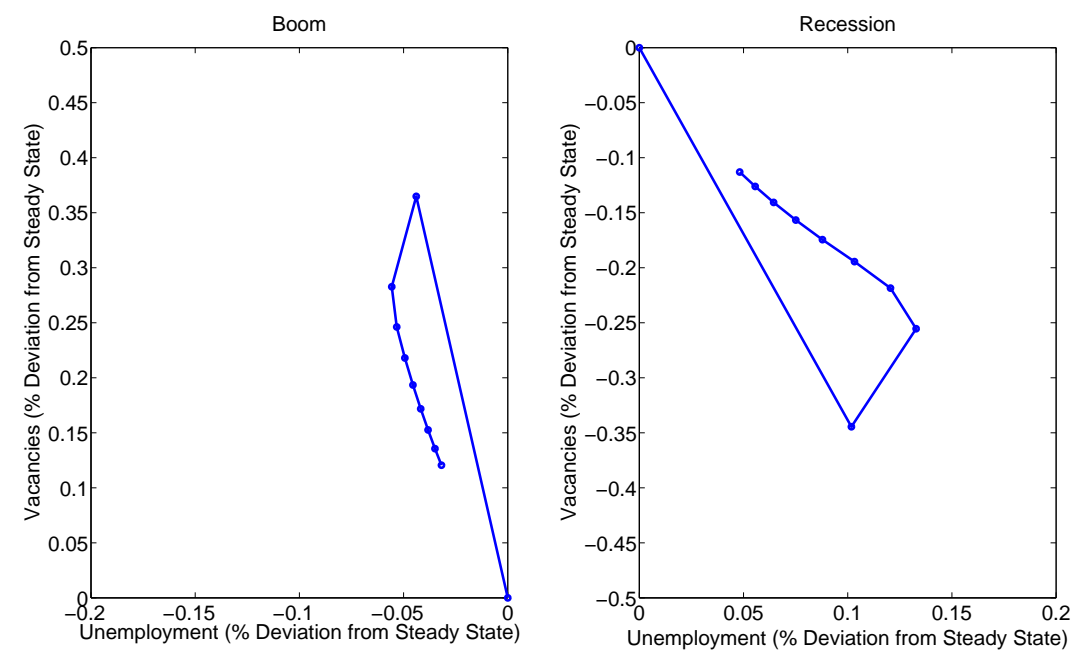

Figure 10: Beveridge curve shift in boom and recession scenario. Model response to a 2.5 positive (left panel) and $2.5 \%$ negative (right panel) productivity shock.

This phenomenon can be illustrated further by looking at the Beveridge curve for the dynamic simulation of the model, based on the actual productivity process for the US, using the Fair and Taylor (1983) shooting algorithm. Figure 11 shows that the simulated Beveridge curve has a particularly 
nonlinear shape in times of high unemployment. This is again very much in line with the corresponding figure based on US data in Section 2.

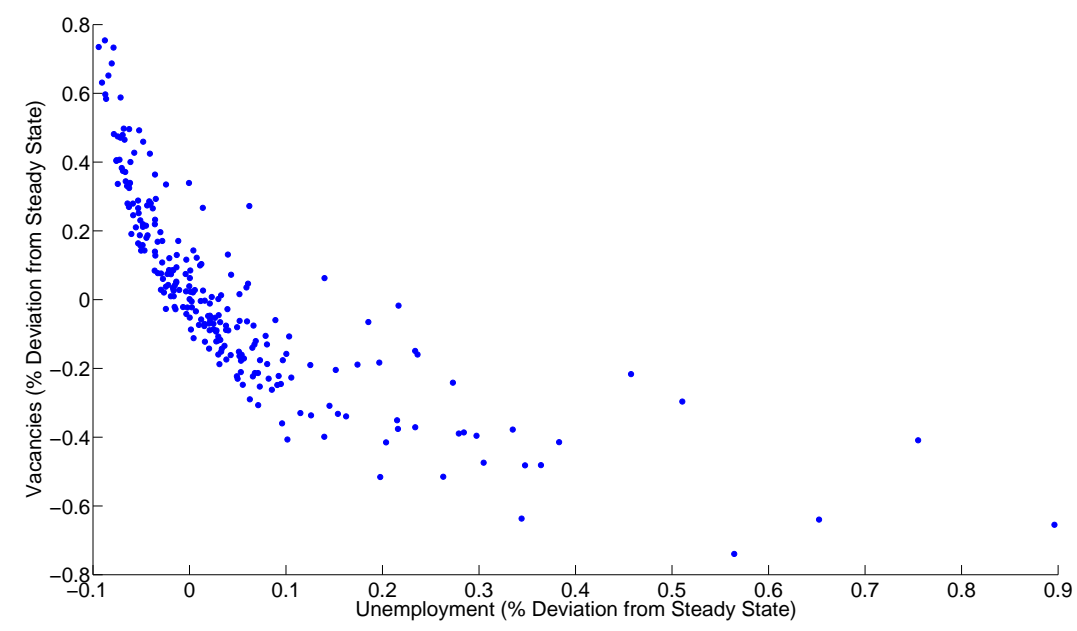

Figure 11: The model-based Beveridge curve.

This nonlinearity is also apparent when looking at the simulated matching function. Figure 12 plots the model generated job-finding rate and market tightness and fits a linear and a nonlinear matching function as in Figure 7 from Section 2. While the fit of the nonlinear matching function is better, it systematically overpredicts the job-finding rate in times of very low and very high market tightness. In Section 4, we explained the driving forces for this mechanism. In severe recessions, the job-finding rate drops by a lot due to the nonlinearities generated by the idiosyncratic productivity density function. By contrast, market tightness drops by less than in a search and matching model due to composition effects. Thus, through the lens of the matching function, it appears as if the job-finding rate has dropped by too much. ${ }^{23}$

In the most extreme economic downturn in our simulation, the job-finding rate falls by more than 50 percent. This leads to a drop of the measured matching efficiency (calculated as the ratio between the actual job-finding rate and its prediction based on the nonlinear matching curve) by about one quarter and shows that our model mechanism generates substantial fluctuations of the measured matching efficiency. ${ }^{24}$ We thereby contribute to the

\footnotetext{
${ }^{23}$ The measured matching efficiency also drops in strong booms in our numerical simulation. The job-finding rate increases by less in a boom than in a recession. At the same time, market tightness does not increase by as much as in a model without labor selection (composition effect). The more moderate reaction of both the job-finding rate and market tightness leads to shifts of the measured matching efficiency, which turns out to be negative in booms in our numerical simulation.

${ }^{24}$ In times of an extreme boom, the matching efficiency also decreases but the effect is
} 


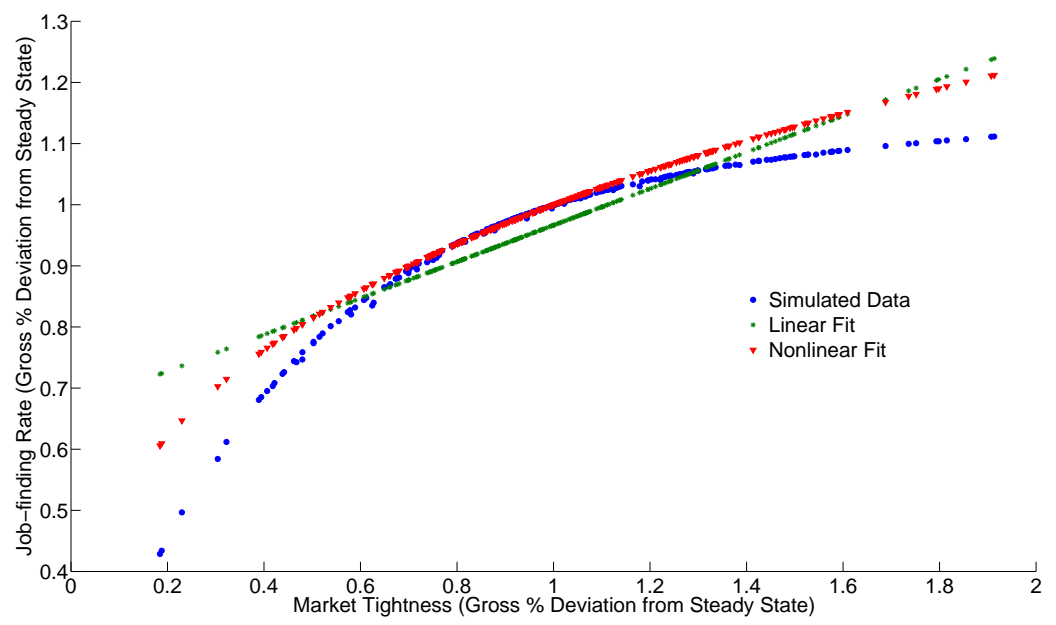

Figure 12: The model-based matching function.

debate on the fall of matching efficiency during severe recessions, which the selection model generates endogenously.

While Christiano et al. (2015) argue that these shifts are quantitatively not important (based on an estimation of a medium-scale model with unemployment), Gavazza et al. (2015) argue that without these shifts the time pattern of the vacancy-filling rate (matches divided by vacancies) cannot be represented appropriately. Gavazza et al. (2015) show that the vacancyfilling rate would increase too much in the Great Recession without a drop of the matching efficiency. Our model mechanism helps to mute this strong increase of the vacancy-filling rate. Matches are the product of contacts and selection. While contacts are driven by the contact function, the selection rate drops very strongly in a severe recession and thus the vacancy-filling rate increases by less than in a model without a selection margin.

Obviously, in recessions there are other factors at work that lead to a decline of the matching efficiency such as mismatch (see Şahin et al., 2014). However, these factors were only found to explain a certain fraction of the actual decline of the matching efficiency in the Great Recession. Thus, we view our mechanism as a complementary explanation for the decline of the measured matching efficiency in recessions.

\subsection{State Dependent Effects}

To illustrate the state dependency of the labor market, we use the simulated labor market time series from the Fair and Taylor (1983) shooting algorithm and calculate standard deviations of different variables for periods

more muted with a maximum drop of $7 \%$. 
when output is below and above trend. Table 2 shows that the job-finding rate and unemployment fluctuate a lot more during downswings than during upswings. This corresponds to the pattern in US data, as illustrated in Section 2.

\begin{tabular}{llllll}
\hline Variable & $U$ & $J F R$ & $V$ & $\theta$ & $Y$ \\
\hline Output Below Median & 0.15 & 0.12 & 0.15 & 0.19 & 0.03 \\
\hline Output Above Median & 0.05 & 0.04 & 0.18 & 0.24 & 0.01
\end{tabular}

Table 2: Standard deviations of different labor market variables during periods when output is below and above median.

The nonlinearities due to the idiosyncratic shock distribution do not only create asymmetric business cycles in the labor market, but they also matter for the effectiveness of policy interventions. To illustrate this point, we assume that the government implements a subsidy of $1 \%$ of productivity for all new and existing worker-firm pairs to stimulate the economy at the beginning of a boom and a recession respectively. The subsidy program exists for half a year and is abandoned afterwards. For illustration purposes, the wage subsidy is financed by lump-sum taxation and thus has no distortionary side effects.

When the government implements the subsidy, the present value of a job increases, vacancy posting rises and the selection rate goes up. To illustrate the nonlinearities, we show how the effects of the policy differ when it is implemented at the beginning of a recession and at the beginning of a boom (corresponding to the $2.5 \%$ productivity shocks from above).

Figure 13 shows the responses of the job-finding rate and unemployment caused by the subsidy in the boom and recession scenario. Interestingly, the effect of the policy on unemployment is several times larger during the recession than during the boom. The intuition is straightforward: The selection cutoff point is at a part of the idiosyncratic density function with more mass during the recession. Thus, the government intervention has a larger effect because a given change in the present value moves the selection rate and thereby unemployment by more.

While we have picked the wage subsidy for illustration purposes and to keep the model simple, our model framework predicts that any policy intervention that affects the net present value of workers and thereby the selection mechanism has stronger employment effects during recessions than during booms. This also holds for government spending if it affects the relative price of labor. This is indeed the case if we embed our framework into a New Keynesian setting. ${ }^{25}$ The time-varying effects of fiscal policy are in line with recent evidence by Auerbach and Gorodnichenko (2012).

\footnotetext{
${ }^{25}$ Results are available on request.
} 

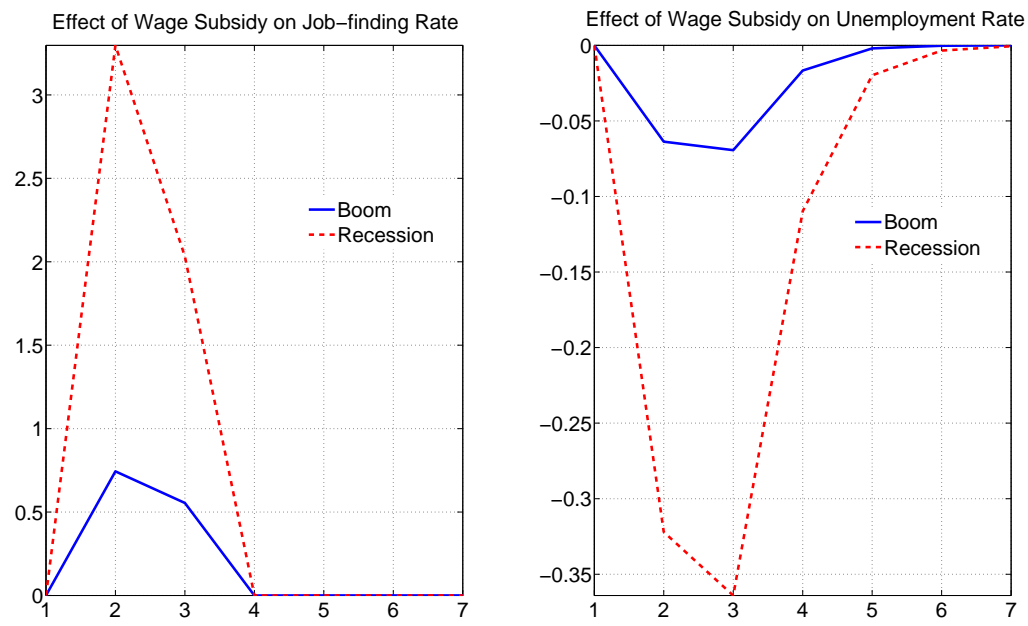

Figure 13: Reaction of unemployment and the job-finding rate in response to a wage subsidy during boom and recession (in percentage points). Deviation from boom and recession scenario without wage subsidy.

Obviously, this section provides only positive statements. However, Chugh et al. (2015) show that an optimal Ramsey planner would choose countercyclical hiring subsidies under the presence of labor selection. Thus, time varying fiscal interventions that affect the present value of workers can be welfare increasing. We leave a detailed analysis of the interaction of the identified nonlinearities and normative issues for future research.

\section{Connection to the Literature}

Our paper is connected to the literature on business cycle asymmetries and to the literature on shifts of the Beveridge curve. This section provides a brief praise of the most relevant papers that we have not discussed so far and puts our contribution in context.

Business cycle asymmetries have been a topic in the empirical literature already a long time ago (e.g. Long and Summers, 1986; Neftçi, 1984). An early theoretical explanation of unemployment asymmetries was provided by Huizinga and Schiantarelli (1992) using a dynamic insider-outsider model with endogenous reservation utility. More recently, McKay and Reis (2008) show that contractions in the United States are briefer and more violent than expansions. They propose a model with asymmetric employment adjustment costs and a choice when to replace old technologies to account for these facts. Abbritti and Fahr (2013) show for various OECD countries that unemployment is skewed over the business cycle.They are able to explain the unemployment asymmetries with a model of asymmetric wage adjust- 
ment costs (i.e. nominal wage cuts are more costly than wage increases). While the asymmetry of (un)employment is well-known, we document that the job-finding rate is very skewed in the United States. We are the first to propose idiosyncratic productivity shocks to be the driving source for this phenomenon.

Search and matching models without idiosyncratic shock for match formation are also able to generate asymmetries of the job-finding rate. However, they either need to rely on some form of wage rigidity (as e.g. PetroskyNadeau and Zhang (2013) who use a Hagedorn and Manovskii (2008) calibration that generates mildly rigid wages) or asymmetric wage adjustment (as Abbritti and Fahr (2013)). Our paper proposes a way of generating asymmetries of the job-finding rate without any wage rigidity. The asymmetry of the job-finding rate is driven by the curvature of the idiosyncratic productivity shock. Thus, we provide an additional complementary mechanism which is useful given that the debate on wage rigidity is still not resolved (Haefke et al., 2013).

Ferraro (2016) proposes in a very recent paper how the Mortensen and Pissarides (1994) framework can be modified to generate labor market asymmetries. He uses heterogeneity in permanent skills as a modeling device. This approach is different from ours where asymmetries arise within a homogenous labor market segment.

The debate on shifts of the matching efficiency was spurred by the Great Recession. Diamond and Şahin (2014) show that Beveridge curve shifts occurred during most post-war recessions in the United States. Barnichon and Figura (2015) discuss reasons for the procyclicality of the matching efficiency (in particular during the Great Recession). Barnichon and Figura (2015) also use heterogeneities as an explanation for shifts in the Beveridge Curve. However, in contrast to us they use systematic differences in search efficiency and labor market segmentation as driving forces, while we use idiosyncratic shocks for match formation. Thus, their theoretical explanation is complementary to ours.

Sedláček (2014) is closest to ours in terms of the shifts of the matching efficiency. He also shows that match efficiency is procyclical and proposes a model with idiosyncratic productivity shocks for both new matches and incumbent workers and firing costs to account for this. Our paper is different in several dimensions: First, we focus on the nonlinear structure of the model, while Sedláček (2014) linearizes the model in order to estimate it. This allows us to also discuss business cycle asymmetries and connect them to shifts of the matching efficiency. Sedláček (2014) estimates a model without idiosyncratic shocks and then calibrates the model with idiosyncratic shocks. Kohlbrecher et al. (2014) show that idiosyncratic shocks for match formation change the elasticity on vacancies/market tightness in the estimated matching function. In other words, if idiosyncratic shocks matter for match formation, the elasticity of matches with respect to vacancies is 
not the same as the coefficient in the theoretical Cobb-Douglas matching function. We use this knowledge in our paper and show that even if this is taken into account, there are additional shifts of the matching efficiency that are due to nonlinearities.

\section{Conclusion}

This paper has shown that the matching function and the Beveridge curve exhibit strong nonlinear patterns in the United States. We have presented a search and matching model with labor selection to explain these phenomena.

Labor selection provides a new rationale for why the measured matching efficiency can be expected to decline in severe recessions. It thereby contributes to the debate on the driving forces of the decline of the matching efficiency during the Great Recession in the United States.

Our model mechanism also explains why certain government interventions can be expected to have time varying effects (depending on the business cycle stage). We leave the integration of this mechanism into a larger scale model and a detailed normative analysis for future research. 


\section{References}

Abbritti, M. And S. FAhr (2013): "Downward Wage Rigidity and Business Cycle Asymmetries," Journal of Monetary Economics, 60, 871-886.

Auerbach, A. J. And Y. Gorodnichenko (2012): "Measuring the Output Responses to Fiscal Policy," American Economic Journal: Economic Policy, 4, 1-27.

BAI, J. AND S. NG (2005): "Tests for Skewness, Kurtosis, and Normality for Time Series Data," Journal of Business 83 Economic Statistics, 23, 49-60.

BARnichon, R. (2010): "Building a Composite Help-Wanted Index," Economics Letters, 109, 175-178.

Barnichon, R. And A. Figura (2015): "Labor Market Heterogeneity and the Aggregate Matching Function," American Economic Journal: Macroeconomics, 7, 222-49.

Brown, A. J. G., C. Merkl, And D. J. Snower (2015): "An Incentive Theory of Matching," Macroeconomic Dynamics, 19, 643-668.

Chow, G. C. And A.-L. Lin (1971): "Best Linear Unbiased Interpolation, Distribution, and Extrapolation of Time Series by Related Series," The Review of Economics and Statistics, 53, 372-75.

Christiano, L. J., M. S. Eichenbaum, And M. Trabandt (2015): "Understanding the Great Recession," American Economic Journal: Macroeconomics, $7,110-67$.

Chugh, S. K., W. Lechthaler, and C. Merkl (2015): "Optimal Fiscal Policy with Labor Selection," Boston College, mimeo.

Chugh, S. K. And C. Merkl (forthcoming): "Efficiency and Labor Market Dynamics in a Model of Labor Selection," International Economic Review.

Diamond, P. A. And A. ŞAhin (2014): "Shifts in the Beveridge Curve," Staff Reports 687, Federal Reserve Bank of New York.

FAiR, R. C. AND J. B. TAYlOR (1983): "Solution and Maximum Likelihood Estimation of Dynamic Nonlinear Rational Expectations Models," Econometrica, 51, 1169-85.

Ferraro, D. (2016): "The Asymmetric Cyclical Behavior of the U.S. Labor Market," Arizona State University, mimeo.

Gavazza, A., S. Mongey, And G. Violante (2015): "What Shifts the Beveridge Curve? Recruitment Effort and Financial Shocks," 2015 Meeting Papers 1079, Society for Economic Dynamics. 
Haefke, C., M. Sonntag, And T. van Rens (2013): "Wage Rigidity and Job Creation," Journal of Monetary Economics, 60, 887 - 899.

Hagedorn, M. And I. Manovskit (2008): "The Cyclical Behavior of Equilibrium Unemployment and Vacancies Revisited," American Economic Review, 98, 1692-1706.

Hochmuth, B., H. Gartner, B. Kohlbrecher, and C. Merkl (2016): "Labor Selection over the Business Cycle: An Empirical Assessment," Friedrich-Alexander-Universität Erlangen-Nürnberg, mimeo.

Hodrick, R. J. And E. C. Prescott (1997): "Postwar U.S. Business Cycles: An Empirical Investigation," Journal of Money, Credit and Banking, $29,1-16$.

Huizinga, F. And F. Schiantarelli (1992): "Dynamics and Asymmetric Adjustment in Insider-Outsider Models," Economic Journal, 102, 1451-66.

Kohlbrecher, B., C. Merkl, and D. Nordmeier (2014): "Revisiting the Matching Function," IZA Discussion Papers 8515, Institute for the Study of Labor (IZA).

Krause, M. U. And T. A. Lubik (2007): "The (Ir)relevance of Real Wage Rigidity in the New Keynesian Model with Search Frictions," Journal of Monetary Economics, 54, 706-727.

Lechthaler, W., C. Merkl, And D. J. Snower (2010): "Monetary Persistence and the Labor Market: A New Perspective," Journal of Economic Dynamics and Control, 34, 968-983.

Long, J. B. D. And L. H. Summers (1986): "Are Business Cycles Symmetric?" NBER Working Papers 1444, National Bureau of Economic Research.

Lubik, T. A. (2013): "The Shifting and Twisting Beveridge Curve: An Aggregate Perspective," Working Paper No. 13-16, Federal Reserce Bank of Richmond.

McKay, A. And R. Reis (2008): "The Brevity and Violence of Contractions and Expansions," Journal of Monetary Economics, 55, 738-751.

Mortensen, D. T. And C. A. Pissarides (1994): "Job Creation and Job Destruction in the Theory of Unemployment," Review of Economic Studies, 61, 397-415.

Neftçı, S. N. (1984): "Are Economic Time Series Asymmetric over the Business Cycle?" Journal of Political Economy, 92, 307-28. 
Petrongolo, B. And C. A. Pissarides (2001): "Looking into the Black Box: A Survey of the Matching Function," Journal of Economic Literature, 39, 390-431.

Petrosky-Nadeau, N. And L. Zhang (2013): "Unemployment Crises," NBER Working Papers 19207, National Bureau of Economic Research.

Pissarides, C. A. (2000): Equilibrium Unemployment Theory, The MIT Press, 2 ed.

Şahin, A., J. Song, G. Topa, And G. L. Violante (2014): "Mismatch Unemployment," American Economic Review, 104, 3529-64.

SEDLÁC̆EK, P. (2014): "Match Efficiency and Firms' Hiring Standards," Journal of Monetary Economics, 62, 123-133.

Shimer, R. (2005): "The Cyclical Behavior of Equilibrium Unemployment and Vacancies," American Economic Review, 95, 25-49.

(2012): "Reassessing the Ins and Outs of Unemployment," Review of Economic Dynamics, 15, 127-148. 


\section{A Data}

We use quarterly data from 1951:I to 2013:II that translate into annual growth rates from 1952:I to 2013:II. We start in 1951 as this is the earliest available date for the Composite Help-wanted Index constructed by Barnichon (2010).

Table A.1: Data

\begin{tabular}{|c|c|c|}
\hline Variable & Description & Source \\
\hline Output & $\begin{array}{l}\text { Real Gross Domestic Product } \\
\text { in } 2005 \text { Dollar }\end{array}$ & NIPA-tables $(\text { FRED })^{1}$ \\
\hline $\begin{array}{l}\text { Job-finding } \\
\text { rate }\end{array}$ & $\begin{array}{l}\text { Job finding probability for un- } \\
\text { employed workers }\end{array}$ & $\begin{array}{l}\text { BLS (FRED) - Calcula- } \\
\text { tion as in Shimer (2012) }\end{array}$ \\
\hline $\begin{array}{l}\text { Unemployment } \\
\text { rate }\end{array}$ & Unemployment Rate & BLS (FRED) \\
\hline Vacancies & Composite Help-wanted Index & from Barnichon $(2010)^{2}$ \\
\hline Vacancy rate & $\begin{array}{l}\text { Constructed as in Diamond } \\
\text { and Şahin }(2014)^{3}\end{array}$ & $\begin{array}{l}\text { from Barnichon (2010), } \\
\text { JOLTS, BLS (FRED) }\end{array}$ \\
\hline $\begin{array}{l}\text { Industrial Pro- } \\
\text { duction }\end{array}$ & Industrial Production Index & $\begin{array}{l}\text { Federal Reserve Board } \\
\text { (FRED) }\end{array}$ \\
\hline $\begin{array}{l}\text { Labor Produc- } \\
\text { tivity }\end{array}$ & $\begin{array}{l}\text { Real Gross Value Added: } \\
\text { GDP/Employment in non- } \\
\text { farm business sector }\end{array}$ & BEA/BLS (FRED) \\
\hline \multicolumn{3}{|c|}{$\begin{array}{l}{ }^{1} \text { FRED: Federal Reserve Bank of St. Louis Economic Database } \\
\text { (http://research.stlouisfed.org/fred2/) } \\
2 \text { Barnichon's Composite Help-wanted Index } \\
\text { (https://sites.google.com/site/regisbarnichon/research) } \\
{ }^{3} \text { Composite Help-wanted Index matched to JOLTS vacancies in December } \\
\text { 2000, JOLTS vacancies from } 2001 \text { onwards; time series divided by civilian } \\
\text { employment. }\end{array}$} \\
\hline
\end{tabular}




\section{B Skewness and Log-Approximation}

\section{B.1 Skewness Measure}

\begin{tabular}{llllll}
\hline Variable & $J F R$ & $U$ & $V$ & $\theta$ & $Y$ \\
\hline Skewness & -0.90 & 2.20 & 0.05 & 0.27 & -0.34 \\
P-Value & 0.01 & 0.05 & 0.38 & 0.19 & 0.02 \\
\hline
\end{tabular}

Table B.2: Business Cycle Skewness. Statistics are based on year-to-year growth rates for quarterly US data from 1951 to 2013. Test statistics for skewness follow Bai and Ng (2005).

\section{B.2 Growth Rates versus Log-Approximation}

We have adopted the standard practice in the business cycle asymmetries literature (e.g. Abbritti and Fahr, 2013) to calculate annual growth rates of various aggregate labor market time series in percent deviations. This Appendix illustrates how our results would change when using a log-approximation instead.

In contrast to other aggregate variables (such as productivity or GDP), labor market variables exhibit very large fluctuations. As a consequence, the approximation of growth rates with the fourth log-differences is not suitable, as illustrated by Figure B.1.
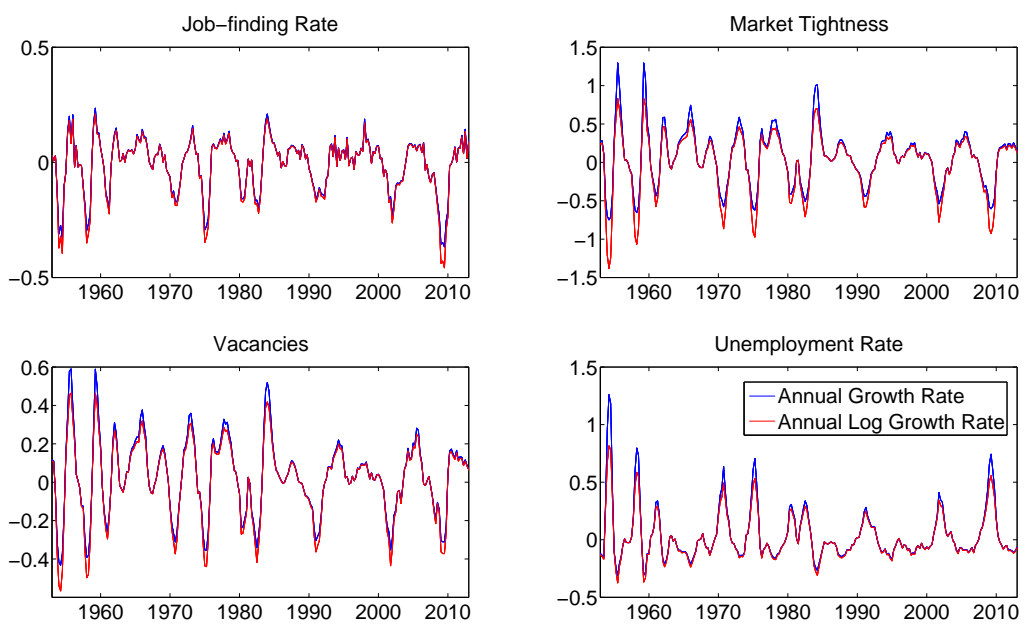

Figure B.1: Growth rates versus log-differences for different time series. 
The approximation mistake is particularly extreme for market tightness, which shows the largest movement of all variables. While the actual annual growth rate of market tightness ranges in between -75 percent and 130 percent, the log-approximation ranges in between -138 percent (which is impossible by definition) and 83 percent. The bottom line is that the logapproximation artificially skews the labor market growth rates downwards.

This would change the nonlinear results from Section 2 dramatically. Given that the job-finding rate fluctuates a lot less than market tightness, the bias is particularly big for the latter. As a consequence, the negative log growth rates of the market tightness become a lot larger and the matching function appears to be almost linear (compare the approximation in the upper panel of Figure B.2 to the real growth rates in the lower panel). However, this is just the result of the approximation mistakes. The same is true for the Beveridge curve.
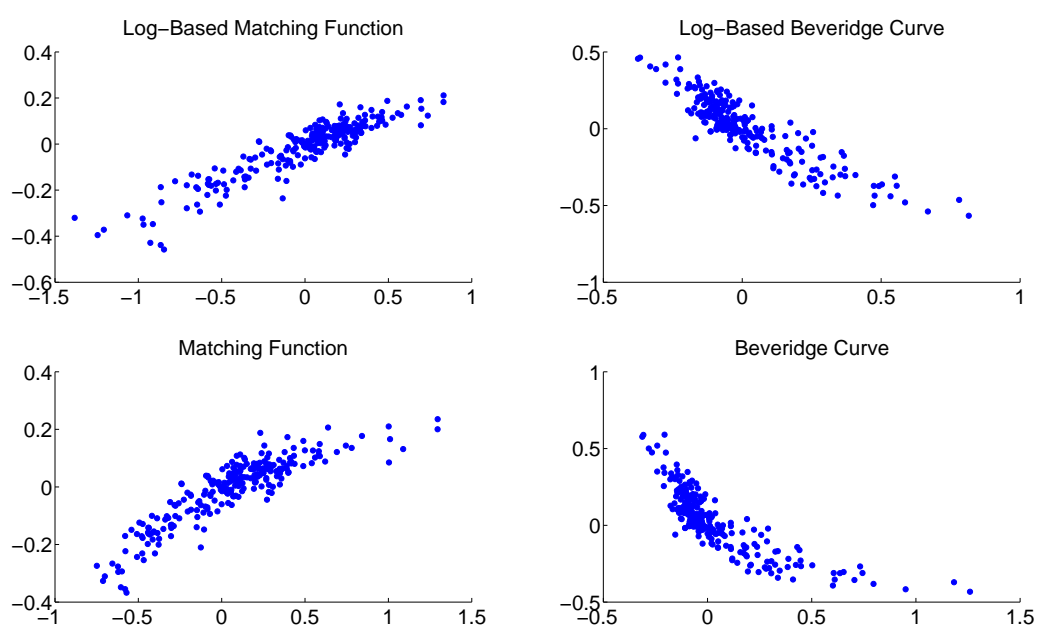

Figure B.2: Growth rates versus log-differences for Beveridge curve and matching function.

Thus, this Appendix sounds a cautionary note on using log-approximation for labor market variables because this may generate misleading results in terms of labor market asymmetries. We believe that the conventional practice of using the logarithm is one of the reasons why the existing literature has not pointed out the nonlinearities of the Beveridge curve and the matching function.

Our critique also applies when using the Hodrick-Prescott filter for logarithmic time series (Hodrick and Prescott, 1997). In addition, the HP filter may generate a skewed trend and thereby mask parts of the phenomenon that is of interest. This would certainly be true for the job-finding rate in 
the Great Recession. We have observed a violent and asymmetric decline of the job-finding rate, which remained below its long-run trend for several years. The HP-filter would smoothly adjust downwards and thereby absorb part of the skewed behavior.

\section{Analytical Appendix}

We have derived a search and matching model with labor selection in the main part. To illustrate that the nonlinearities are driven by the selection mechanism, we separate our model into two analytical parts. First, we analyze the role of nonlinearities and the matching efficiency in a search and matching model without labor selection. Second, we do the same for a selection model with a degenerate contact function $(\gamma=0)$.

\section{C.1 Search and Matching Model}

In steady state, the search and matching model can be expressed in terms of the job-creation condition

$$
p=\left(\frac{a-w}{\kappa(1-\delta(1-\phi))}\right)^{\frac{\gamma}{1-\gamma}}
$$

a wage equation and the employment equation.

\section{C.1.1 Business Cycle Asymmetries}

The ability of a pure search and matching model to generate nonlinearities depends crucially on the wage formation mechanism. To illustrate this, let us assume that wages and productivity comove proportionally (with $w=\alpha a$ ). The job-creation condition becomes:

$$
p=\left(\frac{(1-\alpha) a}{\kappa(1-\delta(1-\phi))}\right)^{\frac{\gamma}{1-\gamma}}
$$

The elasticity of the job-finding rate with respect to productivity is then:

$$
\frac{\partial \ln p}{\partial \ln a}=\frac{\gamma}{1-\gamma}
$$

Clearly, the elasticity is constant and does not change with the level of productivity:

$$
\frac{\partial \ln p}{\partial \ln a \partial a}=0
$$

The search and matching model reacts in symmetric fashion to positive and negative productivity shocks. Under wage rigidity, search and matching 
models are able to generate asymmetric reactions to productivity (unless $\gamma=0.5$, which would again create symmetric reactions of the job-finding rate).

\section{C.1.2 Shifts of the Matching Efficiency}

By definition, in a pure search and matching model the economy operates along a stable contact function. Thus, shifts in the matching efficiency are exogenous events that signal a change of the ability of the labor market to create jobs.

\section{C.2 Selection Model}

In steady state, a selection model can be described by four equations: the wage equation, the cutoff point, the selection rate, and the vacancy free-entry condition. We assume the following wage form:

$$
w\left(\varepsilon_{i}\right)=\bar{w}+\alpha \varepsilon_{i}
$$

with

$$
\bar{w}=\omega(a, \eta, \theta, x) .
$$

The wage has one part which does not depend on idiosyncratic components $\bar{w}=\omega(a, \eta, \theta, x)$ and which is a function of aggregate variables, such as productivity, the selection rate, market tightness, and a vector $x$ of parameters (e.g. bargaining power, unemployment compensation, vacancy posting costs). In addition, the wage depends proportionally on idiosyncratic productivity shocks $\left(\alpha \varepsilon_{i}\right)$. This allows us to show general results, while at the same time nesting the Nash bargained wage as used in the main part of the paper. Given the wage, the remaining steady state equations simplify:

$$
\begin{gathered}
\tilde{\varepsilon}=\frac{\bar{w}-a}{(1-\delta(1-\phi))(1-\alpha)}, \\
\eta=\int_{\tilde{\varepsilon}}^{\infty} f(\varepsilon) d \varepsilon \\
\theta=\frac{p \eta}{\kappa}\left(\frac{a-\bar{w}}{1-\delta(1-\phi)}+\frac{(1-\alpha) \int_{\tilde{\varepsilon}}^{\infty} \varepsilon f(\varepsilon) d \varepsilon}{\eta}\right) \\
=(1-\alpha) \frac{p \eta}{\kappa}\left(\frac{\int_{\tilde{\varepsilon}}^{\infty} \varepsilon f(\varepsilon) d \varepsilon}{\eta}-\tilde{\varepsilon}\right) .
\end{gathered}
$$




\section{C.2.1 Business Cycle Asymmetries}

The job-finding rate is

$$
\eta=\int_{\tilde{\varepsilon}}^{\infty} f(\varepsilon) d \varepsilon
$$

Thus, the first derivative is

$$
\frac{\partial \eta}{\partial a}=-f(\tilde{\varepsilon}) \frac{\partial \tilde{\varepsilon}}{\partial a}>0
$$

Given that $\frac{\partial \tilde{\varepsilon}}{\partial a}<0$, this expression is larger than zero, i.e. higher productivity leads to more hiring.

Business cycle asymmetries can be detected by looking at the second derivative of the selection rate with respect to productivity changes:

$$
\frac{\partial^{2} \eta}{\partial a^{2}}=-f^{\prime}(\tilde{\varepsilon}) \frac{\partial \tilde{\varepsilon}}{\partial a} \frac{\partial \tilde{\varepsilon}}{\partial a}-f(\tilde{\varepsilon}) \frac{\partial^{2} \tilde{\varepsilon}}{\partial a^{2}} .
$$

Using the implicit function theorem, we can derive the first derivative of the cutoff point with respect to productivity:

$$
\frac{\partial \tilde{\varepsilon}}{\partial a}=\frac{\omega_{a}^{\prime}-1}{(1-\alpha)(1-\delta(1-\phi))+f(\tilde{\varepsilon}) \omega_{\eta}^{\prime}+(1-\alpha) \omega_{\theta}^{\prime}},
$$

where $\omega_{a}^{\prime}, \omega_{\eta}^{\prime}$, and $\omega_{\theta}^{\prime}$ denote the partial derivative of $\omega$ (the wage function independent of idiosyncratic productivity) with respect to variables $a, \eta$, and $\theta$ respectively. Let us assume a standard wage formation mechanism: $\bar{w}=\alpha(a+\kappa \theta)+(1-\alpha) b$. In this case, the first derivative is given by:

$$
\partial \tilde{\varepsilon} / \partial a=(-1 /((1-\delta(1-\phi))+\kappa \alpha))<0,
$$

and the second derivative is

$$
\frac{\partial^{2} \tilde{\varepsilon}}{\partial a^{2}}=0 .
$$

Thus, the second term in equation (30) is zero.

It follows that with $f^{\prime}(\tilde{\varepsilon})>0$,

$$
\frac{\partial^{2} \eta}{\partial a^{2}}<0
$$

i.e. the job-finding rate reacts differently to upward and downward shifts of productivity. ${ }^{26}$

If $f^{\prime}(\tilde{\varepsilon})>0$, a positive productivity shock shifts the economy to a part of the idiosyncratic distribution with less density. By contrast, a negative productivity shocks shifts the economy to a thicker part of the idiosyncratic

\footnotetext{
${ }^{26}$ The corresponding elasticity is $\frac{\partial \ln \eta}{\partial \ln a}=-f(\tilde{\varepsilon}) \frac{\partial \tilde{\varepsilon}}{\partial a} \frac{a}{\eta}$. Thus, at a given productivity level $a$ and selection rate $\eta$, the percent reaction to a negative productivity shock is larger than to a positive productivity shock.
} 
distribution. Thus, negative productivity shocks exert a larger effect on the selection rate and thus the job-finding rate.

\section{C.2.2 Shifts of the Measured Matching Efficiency}

Kohlbrecher et al. (2014) show that there is a positive comovement between the job-finding rate and market tightness in a selection model, which is observationally equivalent to a Cobb-Douglas matching function.

Using the implicit function theorem and the above steady state equations, they derive the elasticity of the job-finding rate with respect to productivity and the elasticity of market tightness with respect to productivity:

$$
\begin{aligned}
& \frac{\partial \ln (p \eta)}{\partial \ln a}=\frac{-f(\tilde{\varepsilon}) \frac{\partial \tilde{\varepsilon}}{\partial a} a}{\eta}, \\
& \frac{\partial \ln \theta}{\partial \ln a}=\frac{-\frac{\partial \tilde{\varepsilon}}{\partial a} a}{\frac{\int_{\tilde{\varepsilon}}^{\infty} \varepsilon f(\varepsilon) d \varepsilon}{\eta}-\tilde{\varepsilon}} .
\end{aligned}
$$

By combining the above equations Kohlbrecher et al. (2014) show that the elasticity of the job-finding rate with respect to market tightness, i.e. the coefficient on market tightness (vacancies) usually estimated in a matching function estimation, is given by the following term:

$$
\begin{aligned}
\frac{\partial \ln (p \eta)}{\partial \ln \theta} & =\left(\frac{-f(\tilde{\varepsilon}) \frac{\partial \tilde{\varepsilon}}{\partial a} a}{\eta}\right) /\left(\frac{-\frac{\partial \tilde{\varepsilon}}{\partial a} a}{\frac{\int_{\tilde{\varepsilon}}^{\infty} \varepsilon f(\varepsilon) d \varepsilon}{\eta}-\tilde{\varepsilon}}\right) \\
& =\frac{f(\tilde{\varepsilon})}{\eta}\left(\frac{\int_{\tilde{\varepsilon}}^{\infty} \varepsilon f(\varepsilon) d \varepsilon}{\eta}-\tilde{\varepsilon}\right) \\
& =\frac{\partial \frac{\int_{\tilde{\varepsilon}}^{\infty} \varepsilon f(\varepsilon) d \varepsilon}{\eta}}{\partial \tilde{\varepsilon}} .
\end{aligned}
$$

This term only depends on the distribution of the idiosyncratic shock and the position of the cutoff point. Intuitively, the term describes the first derivative of the conditional expectation of idiosyncratic productivity with respect to the cutoff point.

A graphical illustration for the comovement between the job-finding (selection) rate and market tightness is shown in Figure 8. The elasticity of the job-finding rate with respect to market tightness, i.e. the implied weight on vacancies in an estimated matching function, changes with the position of the cutoff point. If the cutoff point is located at an upward sloping part of the density function, a negative productivity shock moves it to a part of the distribution with more density, which causes the asymmetric response of the job-finding rate. At the same time, the decline of productivity changes 
the relationship between the job-finding rate and market tightness (see lower panel in in Figure 8). The elasticity of the job-finding rate with respect to market tightness increases.

These two effects are not taken into account when estimating a timeinvariant matching function. In a recession, it appears as if for a given change in market tightness the job-finding rate has fallen too much, i.e. the measured matching efficiency decreases when aggregate productivity drops. 